COMMENTARY ON COVID-19 AND THE FoOd SYSTEM

\title{
Walking the nutrition talk: The impact of a community-engaged nonprofit in Selma, Alabama
}

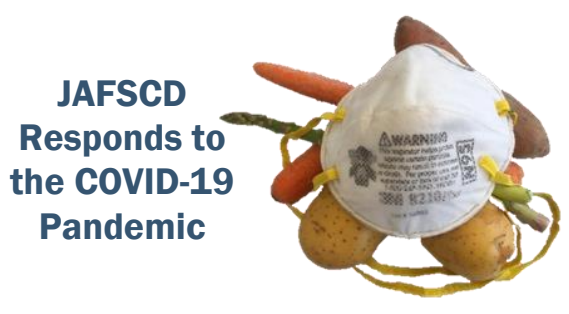

\author{
Susan U. Raymond ${ }^{a *}$ and Chad D. McEachern ${ }^{\mathrm{b}}$ \\ Edmundite Missions
}

Submitted November 23, 2020 / Published online February 18, 2021

Citation: Raymond, S. U., \& McEachern, C. D. (2021). Walking the nutrition talk: The impact of a community-engaged nonprofit in Selma, Alabama. Journal of Agriculture, Food Systems, and Community Development, 10(2), 283-289. https://doi.org/10.5304/jafscd.2021.102.014

Copyright (C 2021 by the Authors. Published by the Lyson Center for Civic Agriculture and Food Systems. Open access under CC-BY license.

\begin{abstract}
COVID-19 and its differential impact on those with compromised health have driven home the fundamental importance of nutrition, which is at the root of much chronic disease among the poor. Edmundite Missions, serving Selma and rural Alabama for 80 years, has demonstrated how the actions of a trusted nonprofit providing holistic services in a deeply and historically impoverished population can improve nutrition, inspire youth leadership on nutrition issues, and while simultaneously driving resources into rural economies. In the process, the work has also shown that the poor do indeed understand the importance of good nutrition and both seek and choose positive nutritional options if they are available. The problem among the poor is not knowledge; it is opportunity.

\section{Keywords}

Nutrition, Poverty, U.S. Black Belt, Rural, Economic Impact, COVID-19 Impact, Pandemic, Selma, Alabama, Youth Leadership, Nonprofits, Dignity

\footnotetext{
a * Corresponding author: Susan U. Raymond, Ph.D., Vice President, Program Integration and Chief Innovation Officer, Edmundite Missions; 1002 Minter Avenue; Selma, AL 36701 USA; +1-334-872-2359; susanr@edmunditemissions.org

${ }^{\mathrm{b}}$ Chad D. McEachern, President and CEO, Edmundite Missions.
} 
$\mathrm{E}$ dmundite Missions is a Catholic nonprofit that has served those living in poverty in Selma, Alabama, and surrounding rural areas since 1937, including as a leader in the civil rights movement. Food has always been in the Missions' DNA. Food assistance began with two priests handing out sandwiches from the back door of the rectory. By 2017, the Missions' Bosco Nutrition Center was serving 1,000 meals a day. During COVID, the number topped 1,500 each day. Another 1,500 weekend breakfasts reach 750 elementary each week, and 250 rural families attended Missions food pantries.

That continued role takes place in the face of five generations of unrelenting poverty.

\section{Poverty and the Black Belt}

The Black Belt ${ }^{1}$ continues to be one of the poorest sections of the nation, with poverty rates more than double the U.S. average. The counties served by the Missions' food programs have average household incomes that are a third of the national average. The clients served by the Missions, at least those who have any income at all, subsist on an average of US\$11,000 per year. Rent and utilities often consume $70 \%-80 \%$ of this amount.

As poverty has persisted, the state of health of the population living with low income has changed. Adult obesity rates in the areas served are $41 \%$ or more, nearly double the national average. Food insecurity is rampant. The U.S. rate is $13 \%$. The Alabama rate is $16 \%$. In the three counties served by the Missions food programs, it ranges from 33\% to 36\%. Diabetes rates in our community are double those of the nation. Early death from cardiovascular disease is common. Indeed, life expectancy in Dallas County, of which Selma is the seat, is on par with that of Bangladesh. With such widespread pre-existing conditions, COVID-19 mortality threatened to hit Selma like a hot knife through butter.

Nutrition lay at the core of many of these problems.

Edmundite Missions can play a pivotal role in improving nutrition in Selma and surrounding rural areas and can provide a model for other nonprofits. We are the primary source, and in some cases the only consistent source, of food for the poor. We have the kitchen production capacity to provide healthy food alternatives and the relationships with smallholder Black farmers that could bring fresh foods into the food pantry process. We have programs that reach every aspect of our community's life. We have the donors to make the effort sustainable.

The question was how to mobilize those assets in the interests of improved nutrition.

Three steps were critical. First, ask people what they want. We believe in the poor. They deserve the dignity of expressing their own views and articulating their own priorities. Second, and guided by the community, change the Missions' approach such that its fundamental food functions would de facto affect community nutrition. In effect, walk our own talk. Third, infuse nutrition throughout all programming.

\section{Conferring With the Community}

Edmundite Missions does not serve a "target audience." We serve in and with the community in which we live. To understand what our communities know about food and what kind of food they want, we used surveys and interviews. Like others working in extremely low income communities, we found no lack of knowledge about what was healthy and no lack of desire for healthy foods. When asked what could be added to our services, fresh fruits and vegetables were at the top of the list.

The problem was not knowledge. The problem was access.

That understanding caused us first to look at ourselves. Were we really nutrition partners to our own

${ }^{1}$ The Black Belt refers to the highly productive soils in an area about 30 miles (48 km) wide and 300 miles (483 km) long stretching across central Alabama and northeastern Mississippi. 
community? However many meals we served, however many groceries we gave away, were we ourselves meeting the desires of our community?

\section{Walking Our Own Talk}

We decided we were not. Simply put, we were feeding, but we were not necessarily nourishing to the extent that our position in the community could enable.

The response strategy was threefold: (1) change the way we approached feeding 1,000 people a day at the Bosco Nutrition Center, (2) upend our rural food programs, and (3) infuse nutrition into every program that wrapped around our community.

In Selma, 18 core recipes used at the Bosco Nutrition Center were reviewed by a registered dietician and totally revised on her advice to reduce salt, sugar, and fats. The inclusion of fried foods in dinner menus was cut in half. Shelf-stable items in lunch bags that are high in fat and sugar were replaced with whole wheat, low salt, and low sugar alternatives. Fresh fruits and vegetables were added at every step of the way. Water was offered as an alternative to juices.

In rural areas, the Missions bade a permanent goodbye to the preselected bag of food and a big hello to local African American smallholder farmers. The rural food pantries shifted to a shopping model based on a point system and a "shopping list" developed by a nutritionist, representing a balanced shopping cart. The points biased selections toward fresh fruits and vegetables. We contacted local African American farmers who could supply those fresh foods and entered into supply agreements. Rural communities are very tightly knit, and those who come to food pantries are often farm families themselves,

\section{Figure 1. Local African American Farmers Deliver Okra to the Missions Market}

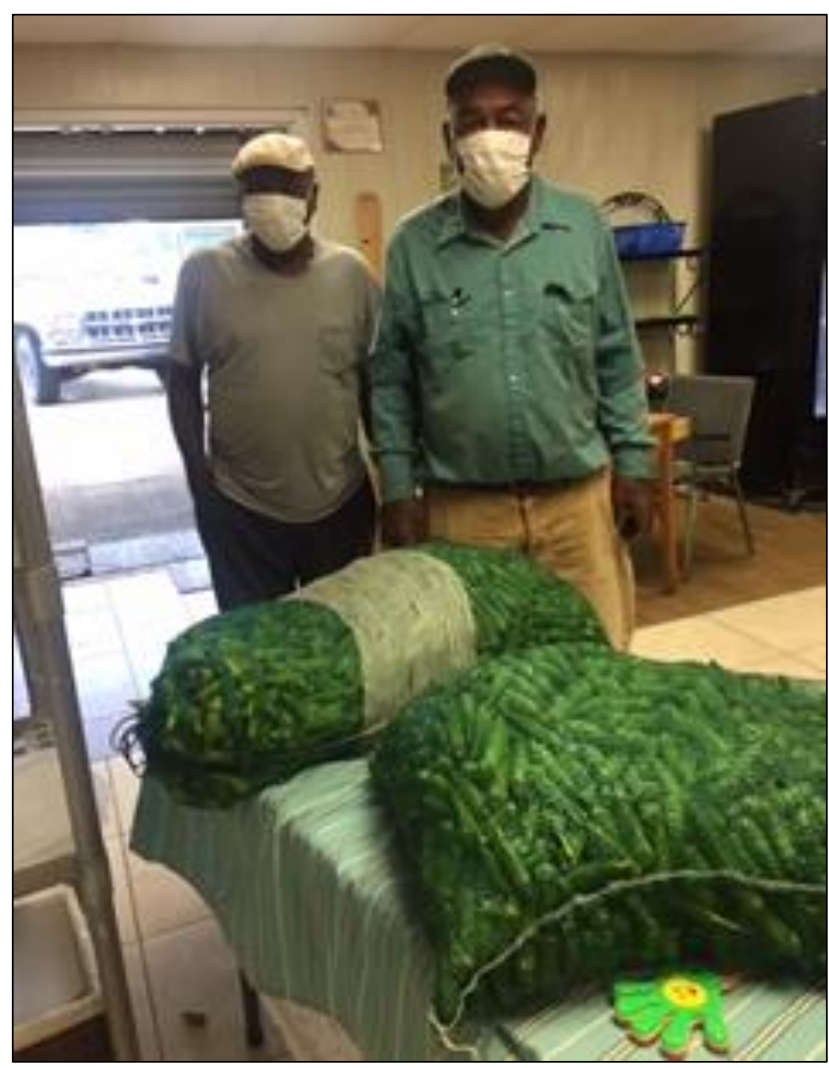
especially where rural incomes are extremely low and smallholder farms dominate. Finding interested farmers was not difficult once the ask was made. The agreements were on a 6-month basis, with items determined jointly depending on the season and the crop. The six-month timeframe provided the farmer with enough forward procurement security to hire extra hands and bring new land into production. Figure 1 shows one of our local farmers and his assistant delivering a load of okra for the Missions market. Locally grown foods have longer shelf lives than fresh foods from food banks, which reduced waste. Partnerships allow us to pivot our procurement away from food banks and to farmers, driving our money into the local economy.

This was all extremely new to our communities. To ensure that the process ran smoothly, every community client received a "personal shopper" for the first two months. This staff member or volunteer shopped with the client, helping to explain the points system and the choices that were now possible. This was essential given the low literacy rates in our communities. It was also essential for an 
unanticipated reason. We discovered that many of our community members were vision-impaired. They could not see either the shopping list or the labels on the food! We were able to register them with the Lions Club sight clinic, as well as bring in "cheater" spectacles that we could hand out at their next visit.

The community's reaction has been insightfully positive. One mother with a four-year-old remarked that with a hungry young one, she would open up the bag and find nothing that he liked. So, the bag was not a solution to hunger. Now, she could choose what her child liked (he happened to have a passion for apples) and have something to feed him. A gentleman client who had been coming to the pantry for years walked into the store, looked around, and said, "This is the best idea you have had in 10 years." He proceeded to shop, chose all fresh fruits and vegetables, and came to the check-out counter. He looked up and asked, "So, can I donate back all the cans?"

One of the great advantages of the Missions in influencing nutrition content and behavior is its scope. The Missions touches the community at all ages in multiple ways. It can wrap nutrition messaging around its clients at all of its touchpoints. The drumbeat of good nutrition can become the percussion section of the Missions service orchestra.

The social service and counseling arm of the Missions added questions about nutrition knowledge and eating behavior to its client intake form. This allowed the initial conversation about needs to introduce a conversation about food.

The after-school New Possibilities Youth Program (NPYP) now includes experiential learning around food and nutrition. The summer camp includes organic gardening, cooking lessons with products from the garden, and preparation of healthy snacks.

During the school year, a reward and recognition system was built into the after-school curriculum. For example, in a two-week unit, time was given over to presentations on nutrition. Each student was then given US\$20, and the class went to Walmart to shop for salad makings. Only fresh foods were allowed. The remaining change had to be returned to the Missions. Students then made salads (which were taken home) accompanied by self-made salad dressings. The final day was a salad dressing "throwdown," with each student recreating his or her dressing and the Bosco Nutrition Center cooks judging the entries. The winner and runner-up were awarded baskets of fresh produce, and their dressings were featured as "Dressing of the Week" at the Bosco Nutrition Center.

For teens, the social context and the behavior of their peers is important. Athletes are often admired and emulated. In Alabama, that means football players. Therefore, the Missions works with the Selma High School athletic program to bring nutrition education to athletic teams. The Missions provides afterpractice and half-time food to the football team and accompanies that with a specific curriculum on nutrition for athletic performance. Every week a different aspect of that intersection is presented with accompanying handouts. The 2019-20 team made it to the regional playoffs for the first time in many years, making believers and school opinion leaders out of the athletes. Indeed, seven seniors formed a "speakers bureau" and reached out to the middle school football teams to start to preach nutrition.

The Missions recognized that emphasizing healthy ingredients and purchasing healthy products would likely increase costs. A careful assessment was made of the budget effect of purchasing changes. While costs did increase, the impact was not as material as had been expected. For example, the switch to whole wheat bread throughout the program increased per sandwich costs by two cents. The total cost effect for the Bosco Nutrition Center is about 3\% of annual operating expenditures.

\section{Impact}

About $70 \%$ of lunch attendees come to Bosco at least four times a week for lunch. One hundresd percent of children in three schools are reached weekly during the school year. Hence, even small changes can make a big difference. 
On an annual basis, changes to lunch and home and school delivery menus (totaling over 360,000 meals a year) result in:

- Reduction of over 19 million calories

- Reduction of fat intake by 1.5 million grams

- Reduction in sugar intake by 400 grams

- Reduction in salt intake by 44 million milligrams

Nearly $90 \%$ of dinner attendees regularly rely on Bosco for their evening meal.

On an annual basis and assuming an average dinner census of 180 individuals (this is a conservative figure as dinner can be upwards of 220 individuals) ${ }^{2}$ and 300 home delivered meals to people with disabilities, the changes result in:

- Reduction of

○ 4.7 million calories

○ 1.8 million grams of fat

○ 3.7 million milligrams of cholesterol

- 11 million milligrams of salt

- 38,000 grams of sugar

- Increase of

- 793,000 grams of protein

○ 96,000 grams of fiber

What does all of this change actually mean in terms of the scale of nutritional impact? It appears to be quite a great deal. Figure 2 illustrates the scale of changes in terms of the equivalent consumption of various items of fast food.

Two years of our efforts teach five lessons about how nonprofits can use the totality of their relationships to improve community nutrition.

First, trust matters. When a nonprofit has been in a community for over 80 years, it is trusted. And trust creates a willingness to listen and participate, and that opens the door to change. Many, many organizations lecture to the poor, most with great sincerity. But the trust that is a product of a deep history of engagement throughout a community opens the door to listening.

Second, scale matters. The Missions is not just the source of food in the Selma community and in rural areas. It is the source of counseling. It is the source of funding to meet family crises. It is the source of after-school programming. How it feeds people, by definition, changes how the community eats. Because a holistic organization touches lives in many different ways at many different times, its ability to bring consistency and constancy to messaging is unparalleled.

Third, dignity matters. Food and nutrition are matters of dignity. Giving people choices about their own food and their own nutrition is important in and of itself as a value because choice reinforces individual freedom and self-reliance. But choice also contributes to effectiveness because choice makes people feel part of the nutrition education and action process.

Fourth, attractiveness and fun matter. Hanging posters and giving lectures will not work. Even

\footnotetext{
2 Note that these calculations used a normal Bosco census. The numbers, and impact, are much greater during the COVID-19 situation. As of August 2020, Bosco is serving over 200 for lunch and well in excess of 400 at dinner.
} 
demonstrating correct behaviors does not work. For people who are deeply impoverished, the daily struggle is survival. Teaching change requires making those changes easy and attractive and memorable. Nutrition education has to be fun. Working with youth in entertaining ways (crushing chips and making grease charts; having one's salad dressing be featured in a dining hall) communicates core principles in ways that will be remembered and acted upon.

Fifth, the solution is not expensive. Food provision in favor of healthy and fresh options does, in fact, cost more than a reliance on canned and pre-prepared alternatives. But the cost differential is not significant. Well managed nonprofits can make those positive nutrition shifts without endangering their budgets.

Figure 2. Fast-Food Equivalents of Nutrition Improvements in Meals by Edmundite Missions

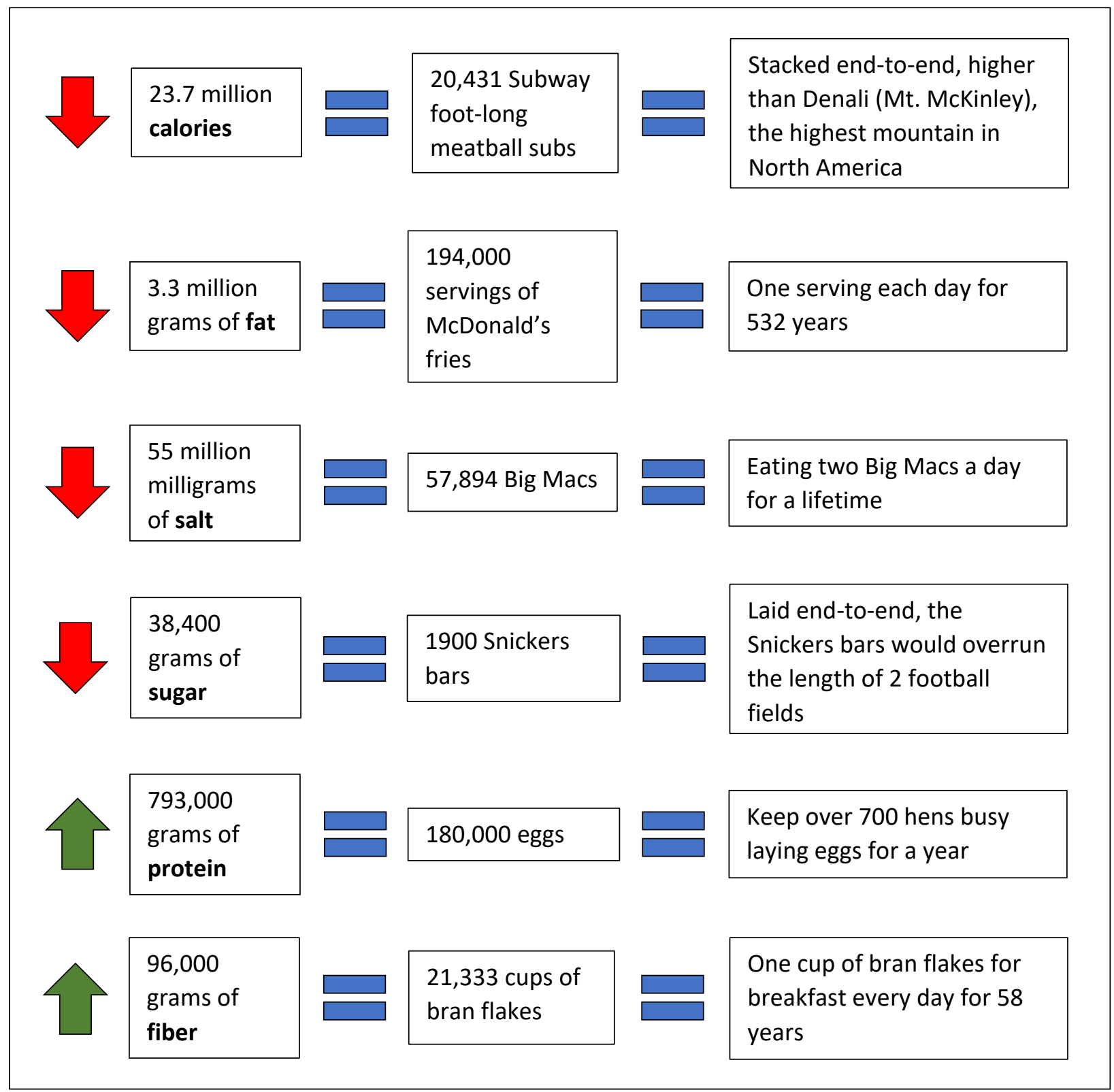




\section{A Final Thought}

Poverty is not necessarily a barrier to nutrition when nonprofit service providers embrace the importance of nutrition and integrate it into everything they do.

Today, as we experience the symbiosis between morbidity and mortality from infectious diseases and the scourge of chronic disease, the importance of nonprofit leadership in including nutrition as a fundamental core of what and how they serve the poor is essential to community health and well-being.

When implemented in an atmosphere of deep trust with a premium on creating and honoring individual dignity, both food provision and food experience-infused throughout integrated services-can have both nutrition and economic impact. 